\title{
Adjuvant Endocrine Therapy in Hormone Receptor-Positive Postmenopausal Breast Cancer: Evolution of NCCN, ASCO, and St Gallen Recommendations
}

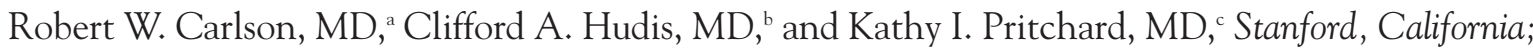 \\ New York, New York; and Toronto, Ontario, Canada
}

\section{Key Words}

Adjuvant therapy, breast cancer, tamoxifen, aromatase inhibitor, NCCN Clinical Practice Guidelines, ASCO Technology Assessment, St Gallen Consensus

\begin{abstract}
Endocrine therapy has a firm role in adjuvant treatment of women with hormone receptor-positive invasive breast cancer. Until recently, tamoxifen was the most commonly used adjuvant endocrine therapy in premenopausal and postmenopausal women. Several randomized clinical trials have studied the third-generation selective aromatase inhibitors (Als) (anastrozole, letrozole, and exemestane) as adjuvant endocrine therapy in postmenopausal women. These studies compared therapy with an Al alone versus tamoxifen alone; 2 to 3 years of tamoxifen followed by switching to an Al versus continuation of tamoxifen; or extended therapy with an Al after approximately 5 years of tamoxifen therapy. No statistically significant differences in overall survival were observed. A single trial using extended treatment with an adjuvant Al suggests a small, statistically significant survival advantage in women with axillary lymph node-positive disease while showing no statistically significant decrease in survival with the use of an Al. The toxicities of the
\end{abstract}

From the aDepartment of Medicine, Stanford University, Stanford, California; ${ }^{\circ B}$ Breast Cancer Medicine Service, Memorial SloanKettering Cancer Center, New York, New York; and 'Toronto Sunnybrook Regional Cancer Centre, Toronto, Ontario, Canada. Submitted March 6, 2006; accepted for publication August 8, 2006. Dr. Carlson has received consulting fees and grant support from AstraZeneca Pharmaceuticals and consulting fees from Pfizer, Inc. Dr. Hudis has received indirect consulting fees and grant support for members of his team from AstraZeneca Pharmaceuticals,

Novartis, and Pfizer. Dr. Pritchard has received consulting fees and grant support directly or indirectly from AstraZeneca

Pharmaceuticals, Novartis, and Pfizer.

Correspondence: Robert W. Carlson, MD, Department of Medicine, Stanford University, 875 Blake Wilbur Drive, Stanford, CA 94305-

5826. E-mail: rcarlson@stanford.edu
Als are generally acceptable, with fewer endometrial cancers, gynecologic complaints, and thromboembolic events, but more bone fractures and arthralgias compared with tamoxifen alone. Three widely disseminated treatment guidelines, the National Comprehensive Cancer Network Breast Cancer Clinical Practice Guidelines in Oncology, the American Society of Clinical Oncology Technology Assessment on the Use of Aromatase Inhibitors, and the St Gallen International Expert Consensus on the Primary Therapy of Early Breast Cancer, now incorporate Als in the adjuvant therapy of postmenopausal women with estrogen receptor-positive breast cancer. (JNCCN 2006;4:971-979)

Adjuvant endocrine therapy is a well-established treatment modality for women with hormone receptorpositive breast cancer. For many years, tamoxifen, a selective estrogen receptor modulator, has been the gold standard of adjuvant endocrine therapy, especially in early breast cancer in pre- and postmenopausal women. ${ }^{1}$ Tamoxifen also has associated toxicities, including hot flushes, thromboembolic disease, endometrial carcinoma, and cataracts. ${ }^{2}$

The effectiveness of selective aromatase inhibitors (AIs) in treating postmenopausal women with hormone receptor-positive metastatic breast cancer has led to various clinical trials testing the use of selective AIs in the adjuvant setting. The studies vary in patient selection; timing and duration of tamoxifen and AI therapy; definition of study end points; and the specific AI used. Furthermore, the available follow-up of most studies is short. Because of the complexity of the studies, expert panels have developed several treatment guidelines to guide clinicians and patients in selecting optimal adjuvant endocrine therapy. 
Carlson et al.

\section{Importance of Practice Guidelines}

Clinical practice guidelines have been defined by the Institute of Medicine as "systematically developed statements designed to assist practitioner and patient decisions about appropriate healthcare for specific clinical circumstances." ${ }^{3}$ These guidelines may be particularly helpful in situations where the available clinical and scientific evidence is rapidly evolving and major changes in practice are necessary. Clinical practice guidelines are ideally developed by a panel of experts representing multiple disciplines and perspectives. ${ }^{4,5}$ Conflicts of interest may arise in the development of clinical guidelines. Recognizing potential conflicts of interest, whether financial, academic, or of another nature, is important to minimize bias in guideline development. ${ }^{5}$

Clinical practice guidelines have several benefits for healthcare delivery. They facilitate the delivery of optimal health care by providing evidence-based recommendations generated by panels of experts. They also help assure consistent evidence-based treatment in differing clinical care situations across the spectrum of geography, governmental healthcare systems, levels of funding, and availability of clinical experts.

Clinical practice guidelines also have direct and indirect benefits for patients.

Improvement in outcomes, as anticipated by the use of evidence-based clinical practice guidelines, should directly improve the quality of patient care. Furthermore, the availability of clinical practice guidelines directed at patients enables them to participate in the clinical decision-making process. Clinical practice guidelines also assist healthcare delivery systems and healthcare payers to efficiently and objectively identify standard options for clinical care.

Several clinical practice guidelines have been developed that specifically assist clinicians and patients in the decision-making process regarding optimal adjuvant endocrine therapy for treating postmenopausal women with hormone receptor-positive breast cancer. This article discusses 3 of these practice guidelines - the National Comprehensive Cancer Network (NCCN) Breast Cancer Clinical Practice Guidelines in Oncology, the American Society of Clinical Oncology (ASCO) Technology Assessment on the Use of Aromatase Inhibitors in the Adjuvant Setting, and the St Gallen International Expert Consensus on the Primary Therapy of Early Breast Cancer-and the clinical trials that formed the basis of these guidelines.

\section{Major Clinical Trials of Adjuvant Hormonal Therapy}

\section{Tamoxifen Trials}

The Early Breast Cancer Trialists' Collaborative Group overview analysis performed a comprehensive metaanalysis of adjuvant tamoxifen therapy. ${ }^{6}$ This analysis documented an approximate 39\% reduction in the annual odds of recurrence (ratio of annual event rates $=0.605$, standard error [SE], 0.028; $P<.00001)$ and a $31 \%$ reduction in the annual odds of death (ratio of annual death rates $=0.683, \mathrm{SE}, 0.036 ; P<.00001$ ) with the use of 5 years of adjuvant tamoxifen in women with estrogen receptor-positive or -unknown breast cancer. ${ }^{6}$ These risk reductions from tamoxifen are largely independent of dose, chemotherapy, patient age, disease nodal status, or duration of follow-up. ${ }^{6}$ Durations of tamoxifen therapy shorter than 5 years (1 or 2 years of therapy) provide benefits in reducing recurrence and death that are smaller than those provided by tamoxifen therapy for approximately 5 years. ${ }^{6}$ Comparisons of longer durations of adjuvant tamoxifen ( 5 vs. 10 years) are not mature enough to be included in the overview analysis.

The National Surgical Adjuvant Breast and Bowel Project B-14 was a clinical trial involving 1172 women with estrogen receptor-positive, axillary lymph node-negative breast cancer who were randomized to treatment with tamoxifen for 5 years versus placebo for 5 years. ${ }^{7,8}$ After this trial showed the superiority of tamoxifen, women who had initially been randomized to treatment with tamoxifen were further randomized to stop tamoxifen at 5 years versus completing a full 10-year treatment course. This trial showed that the longer duration of tamoxifen is associated with a significant reduction in disease-free survival (DFS) ( $78 \%$ vs. $82 \%$ at 7 years; $P=.03$ ) and overall survival (91\% vs. $94 \%$ at 7 years; $P=.07){ }^{7}$

Two additional smaller studies have addressed durations of adjuvant tamoxifen therapy of longer than 5 years. The Scottish Adjuvant Tamoxifen Trial studied the use of 5 years of immediate tamoxifen after mastectomy versus initiation of tamoxifen at first relapse. Women initially randomized to treatment with 5 years of tamoxifen were further randomized, if they provided consent, to stop tamoxifen at 5 years or continue tamoxifen indefinitely until relapse or death. ${ }^{9}$ Of the 342 women further randomized after 5 years of immediate tamoxifen, no additional benefit to continuing 
Adjuvant Endocrine Therapy Practice Guidelines

tamoxifen beyond 5 years was seen at a median followup of 15 years. ${ }^{9}$

The Eastern Cooperative Oncology Group reported a trial of tamoxifen for 5 years versus continuing therapy beyond 5 years. ${ }^{10} \mathrm{~W}$ ith 193 women enrolled after an initial 5 years of tamoxifen and a median follow-up of 5.6 years from randomization, no statistically significant differences were observed in DFS (73\% 5-year DFS with observation vs. $85 \%$ with further tamoxifen; $P=.10$ ) or overall survival (5-year overall survival $89 \%$ with observation vs. $86 \%$ with further tamoxifen; $P=.52) .{ }^{10}$ Thus, available data do not support continuation of tamoxifen beyond an initial 5 years of adjuvant therapy. ${ }^{11}$

\section{Major Adjuvant Trials of Als}

The selective AIs have been studied in several trials of varying design (Figure 1). These trials have compared initial adjuvant therapy with an AI versus tamoxifen; 2 to 3 years of tamoxifen followed by continuation of tamoxifen to complete 5 years versus switching to an AI to complete a total of 5 years of therapy; or a full 5-year course of tamoxifen followed by extended adjuvant therapy for 5 years with an AI versus placebo. No direct comparisons of these 3 different strategies have been reported. All of the trials were limited to women who were postmenopausal at randomization. The AIs do not adequately suppress ovarian estrogen synthesis in premenopausal women, and the results discussed here do not apply to this particular patient population.

Initial Adjuvant Therapy: The Arimidex, Tamoxifen, Alone or in Combination (ATAC) trial enrolled 9366 postmenopausal women with localized invasive breast cancer. Patients in the study were not selected for enrollment based on hormone receptor status. Patients underwent appropriate local surgical treatment with or without radiation therapy and with or without chemotherapy at their physician's discretion. They were subsequently randomized to treatment with anastrozole versus tamoxifen versus both anastrozole and tamoxifen, all for 5 years. Results of the ATAC trial were first presented in December $2001^{12}$ and have been updated in formal publications. ${ }^{13-15}$ Analyses at 33 and 47 months of median follow-up showed that the combination of anastrozole plus tamoxifen was no better than tamoxifen alone, and the tamoxifen plus anastrozole arm of the trial was unblinded and discontinued. ${ }^{13-15}$

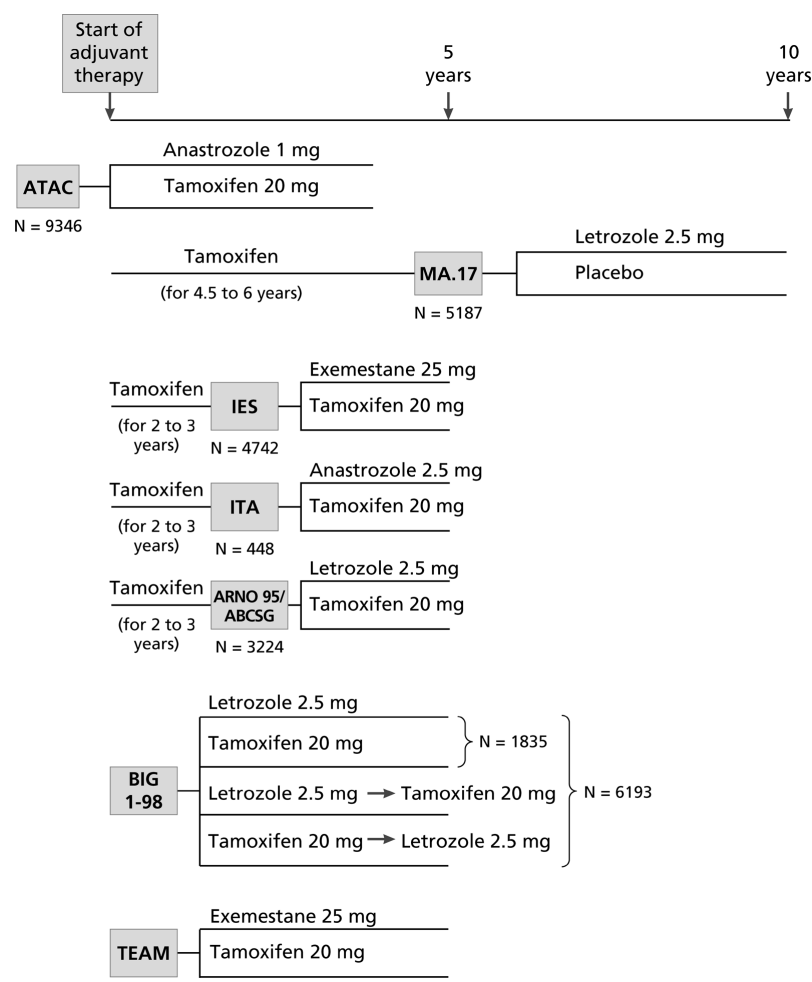

Figure 1 Design of clinical trials of adjuvant aromatase inhibitors (AIs). The box identifying the specific trial denotes the point of enrollment and randomization in the course of therapy.

Abbreviations: ABCSG, Austrian Breast and Colorectal Cancer Study Group Trial 8; ARNO 95, Arimidex-Nolvadex 95 Trial; ATAC, Arimidex, Tamoxifen, Alone or in Combination; BIG, Breast International Group; IES, Intergroup Exemestane Study; ITA, Italian Tamoxifen Anastrozole.

In reports at 33,47 , and 68 months median follow-up comparing anastrozole with tamoxifen showed that improvement in DFS and time to recurrence favored anastrozole. ${ }^{13-15}$ The most recent update at 68 months median follow-up showed that the DFS hazard ratio (HR) was 0.87 (95\% confidence interval [CI], 0.78-0.97; $P=.01)$ and time to recurrence $\mathrm{HR}$ was $0.79(95 \% \mathrm{CI}, 0.70-0.90 ; P=.0005)$, both favoring anastrozole. ${ }^{15}$ Subset analysis in patients with hormone receptor-positive disease confirmed the advantage of anastrozole in DFS (HR, 0.83; 95\% CI, $0.73-0.94 ; P=.005)$ and recurrence (HR, 0.74; $95 \%$ CI, 0.64-0.87; $P=.0002)$. No difference in overall survival has been shown in the ATAC trial (HR, 0.97; 95\% CI, 0.85-1.12; $P=0.7) .{ }^{15}$

Assessment of tolerability in the ATAC trial documented that fewer patients assigned to anastrozole than tamoxifen withdrew from treatment because of adverse effects $(11.1 \%$ vs. $14.3 \% ; P=.0002) .{ }^{15}$ Other toxicities favoring anastrozole over tamoxifen included endometrial carcinoma $(0.2 \%$ vs. $0.8 \% ; P=.02)$, 
venous thromboembolic events $(2.8 \%$ vs. $4.5 \%$; $P=.0004)$, cerebrovascular events $(2.0 \%$ vs. $2.8 \%$; $P=.03)$, hot flushes $(35.7 \%$ vs. $40.9 \% ; P<.0001)$, vaginal bleeding $(5.4 \%$ vs. $10.2 \% ; P<.0001)$, or vaginal discharge $(3.5 \%$ vs. $13.2 \% ; P<.0001)$. Toxicities favoring tamoxifen over anastrozole included bone fractures $(7.7 \%$ vs. $11.0 \% ; P<.0001)$ and arthralgias (29.4\% vs. $35.6 \% ; P<.0001) .{ }^{15}$

The Breast International Group (BIG) 1-98 trial randomized postmenopausal women with hormone receptor-positive breast cancer among 4 treatment arms: letrozole alone for 5 years, tamoxifen alone for 5 years, letrozole for 2 years followed by tamoxifen for 3 years, or tamoxifen for 2 years followed by letrozole for 3 years. ${ }^{16}$ The first analysis of these data focuses on comparing tamoxifen with letrozole, including the patients in the letrozole alone and tamoxifen alone arms plus the patients assigned to the sequential arms, but the patients in the switching arms censored at switching. ${ }^{17}$ At a median follow-up of 25.8 months with 8010 women included in the analysis, DFS was superior in the women treated with letrozole (HR, $0.81 ; 95 \% \mathrm{CI}$, $0.70-0.93 ; P=.003) .{ }^{17}$

Two to Three Years of Tamoxifen Followed by AI: The Intergroup Exemestane Study (IES) of adjuvant tamoxifen therapy enrolled 4742 postmenopausal women with estrogen receptor-positive or -unknown breast cancer who were disease-free after 2 to 3 years of adjuvant tamoxifen. ${ }^{18}$ The women were randomized to either continue treatment with tamoxifen for 5 years or switch to exemestane to complete 5 years of endocrine therapy. At a median follow-up of 30.6 months, the women who switched to exemestane had superior DFS of $91.5 \%$ compared with $86.8 \%$ for those who continued tamoxifen (HR, $0.68 ; 95 \% \mathrm{CI}, 0.56-0.82 ; P=.00005)$; no difference in overall survival was seen $(\mathrm{HR}, 0.88 ; 95 \% \mathrm{CI}$, $0.67-1.16 ; P=.37$ ).

Analysis of adverse events in the IES trial documented that exemestane was superior to tamoxifen in the frequency of gynecologic symptoms $(5.8 \%$ vs. $9.0 \%)$, vaginal bleeding $(4.0 \%$ vs. $5.5 \%)$, muscle cramps ( $2.8 \%$ vs. $4.4 \%)$, and thromboembolic disease $(1.0 \%$ vs. $1.9 \%){ }^{18}$ Tamoxifen was superior to exemestane in the frequency of visual disturbances ( $5.7 \%$ vs. $7.4 \%$ ), osteoporosis ( $5.7 \%$ vs. $7.4 \%$ ), arthralgias $(3.6 \%$ vs. $5.4 \%)$, and diarrhea (2.3\% vs. $4.3 \%)$.

Early results of the Italian Tamoxifen Anastrozole (ITA) trial have recently been reported. ${ }^{19}$ In this trial,
448 postmenopausal women with axillary lymph nodeand estrogen receptor-positive breast cancer were treated with an initial 2 to 3 years of tamoxifen therapy before study enrollment. At study enrollment, they were randomized to either continue treatment with tamoxifen for 5 years or switch to anastrozole for 5 years. At a median follow-up of 36 months, DFS was superior in patients switched to anastrozole (HR, 0.35; $95 \%$ CI, 0.18-0.68; $P=.001)$. No statistically significant difference in overall survival was seen. Gastrointestinal symptoms (7.9\% vs. 2.7\%) and lipid metabolism disorders (9.3\% vs. $4.0 \%$ ) were more common with anastrozole than tamoxifen and gynecologic changes were more common with tamoxifen than anastrozole ( $11.3 \%$ vs. $1.0 \%)$.

The early results of a prospectively designed combined analysis of the Austrian Breast and Colorectal Cancer Study Group (ABCSG) trial 8 and the Arimidex-Nolvadex (ARNO) 95 trial were also reported recently. ${ }^{20}$ In this trial, 3224 postmenopausal women with hormone-sensitive early breast cancer who had completed 2 years of adjuvant tamoxifen therapy were randomized to either complete 5 years of adjuvant tamoxifen therapy or switch to anastrozole to complete 5 years of adjuvant therapy. ${ }^{20}$ At a median of 28 months of follow-up, eventfree survival was superior in women switched to anastrozole (HR, 0.60; 95\% CI, 0.44-0.81; P = .0009). ${ }^{20}$ No statistically significant difference in overall survival was observed. Adverse events that were more frequent in the anastrozole-treated women included bone fractures ( $2 \%$ vs. $1 \%$ ) and nausea ( $2 \%$ vs. $<1 \%) .{ }^{20}$

Approximately Five Years of Tamoxifen Followed by AI: The MA.17 trial enrolled 5187 postmenopausal women who had completed 4.5 to 6 years of adjuvant therapy with tamoxifen for hormone receptor-positive breast cancer. ${ }^{21}$ The women were randomized to a planned 5 years of letrozole or 5 years of placebo. At a median follow-up of 30 months since randomization, the women in the letrozole treatment group had significantly superior DFS at 4 years $(94.4 \%$ vs. $89.8 \%$; HR, $0.58 ; 95 \% \mathrm{CI}$, $0.45-0.76 ; P<.001)$ and no difference in overall survival at 4 years $(95.4 \%$ vs. $95.0 \%$; HR, $0.82 ; 95 \%$ CI, 0.57-1.19; $P=.3)$. A planned subset analysis found that overall survival was significantly improved with letrozole in women with axillary lymph node-positive breast cancer (HR, 0.61; 95\% CI, 
$0.38-0.98 ; P=.04)$, but not in women with axillary lymph node-negative breast cancer (HR, 1.52; 95\% CI, 0.76-3.06; $P=$ not stated). The MA.17 trial was unblinded, and patients were offered cross-over to treatment with letrozole after the initial evaluation at 30 months median follow-up.

\section{Lessons Learned From Adjuvant Trials}

The available randomized clinical trials using AIs in the adjuvant endocrine therapy of postmenopausal women with hormone receptor-positive breast cancer consistently show superior DFS when treatment incorporates an AI as initial adjuvant therapy, switches to an AI after 2 to 3 years of tamoxifen, or extends adjuvant therapy with an AI after approximately 5 years of tamoxifen adjuvant therapy (Table 1). Only the MA.17 trial has shown a survival advantage for AI therapy, albeit a small absolute advantage that was shown only in the axillary lymph node-positive subset of patients. Other large trials of AIs, including the ATAC, IES, ITA, BIG 1-98, and ABCSG 8/ARNO 95 trials, have reported significant improvements in end points such as DFS, time to recurrence, and time to distant recurrence, but not in overall survival. In each of these trials, significant differences in overall survival are expected to emerge with longer follow-up. Trials in which most patients have a good prognosis (e.g., are node-negative or undergo breast conservation surgery) and trials comparing active treatments (AI vs. tamoxifen rather than AI vs. placebo) are also expected to require longer follow-up to show overall survival differences. ${ }^{23}$ Although the toxicity experi- enced varies slightly from trial to trial, treatment incorporating the AIs is generally well-tolerated, with a favorable toxicity profile that differs from tamoxifen alone. Increased toxicities with AIs generally include gastrointestinal toxicity, arthralgias, and bone fractures, with decreases in the frequency of gynecologic toxicities and thromboembolic disease, all compared with tamoxifen.

\section{Updated Guidelines for Adjuvant Endocrine Therapy of Postmenopausal Women}

\section{NCCN Guidelines}

The NCCN Breast Cancer Guidelines represent a comprehensive set of treatment guidelines across the spectrum of breast cancer care. ${ }^{24-26}$ Updated guidelines have been issued annually since 1996 and are designed to assist oncologists in managing patients. These guidelines are developed using the evidence-based consensus process. The panel is composed of breast cancer experts selected from the 20 member institutions of the NCCN. The panel includes representation from surgery, radiation oncology, medical oncology, pathology, and patient advocacy. Panel members are required to disclose any conflicts of interest before each panel meeting. Guidelines are developed using an iterative process with an annual 2-to 3-day panel meeting where formal presentations of available evidence are made and a consensus is established. The guidelines are based on the extent of available evidence, whereas

\begin{tabular}{|c|c|c|c|c|c|}
\hline Study & Al & Setting & Median Follow-Up & HR $(95 \% \mathrm{Cl})$ & $P$ Value \\
\hline ATAC $^{15}$ & Anastrozole & Initial & $68 \mathrm{mo}$ & $0.87(0.78-0.97)$ & .01 \\
\hline BIG 1-98 ${ }^{17}$ & Letrozole & Initial & $25.8 \mathrm{mo}$ & $0.81(0.70-0.93)$ & .003 \\
\hline IES ${ }^{18}$ & Exemestane & Switch & $30.6 \mathrm{mo}$ & $0.68(0.56-0.82)$ & .00005 \\
\hline ITA ${ }^{22}$ & Anastrozole & Switch & $3 y$ & $0.35(0.18-0.68)$ & .001 \\
\hline $\begin{array}{l}\text { ARNO-95/ } \\
\text { ABCSG-8 }\end{array}$ & Anastrozole & Switch & $28 \mathrm{mo}$ & $0.60(0.44-0.81)$ & .0009 \\
\hline MA. $17^{21}$ & Letrozole & Extended & $2.5 \mathrm{y}$ & $0.58(0.45-0.76)$ & $<.001$ \\
\hline
\end{tabular}

${ }^{a}$ Cross-study comparisons must be made with caution as the patient populations, definitions of menopause, definitions of endpoints for analysis, and periods of follow-up differ among the studies.

${ }^{b}$ Combined analysis.

Abbreviations: ABCSC-8, Austrian Breast and Colorectal Cancer Study Group Trial 8; Al, aromatase inhibitor; ARNO-95, ArimidexNovladex 95 Trial; Cl, confidence interval; DFS, disease-free survival; HR, hazard ratio; IES, Intergroup Exemestane Study; ITA, Italian Tamoxifen Anastrozole. 
Carlson et al.

the consensus process allows recommendations across the continuum of breast cancer care to be made in situations where high-level evidence is lacking. ${ }^{26}$

Until January 2002, when the first modification relating to adjuvant AIs in postmenopausal women with hormone receptor-positive breast cancer was made, tamoxifen was the only adjuvant hormonal therapy recommended by the NCCN guidelines for postmenopausal women. ${ }^{24}$ In 2002 , the NCCN revised its breast cancer treatment guidelines to allow anastrozole as an initial adjuvant therapy option for postmenopausal women with hormone receptor-positive breast cancer. Subsequent versions of the NCCN guidelines progressively acknowledge the role of AIs as initial adjuvant hormonal therapy, sequential adjuvant therapy with tamoxifen, and extended therapy after completion of 5 years of tamoxifen. ${ }^{25,26}$

According to the 2006 NCCN Breast Cancer Guidelines, patients with hormone receptor-positive breast cancer should be considered for adjuvant endocrine therapy regardless of age, menopausal status, axillary lymph node status, HER2/neu level of expression, and whether adjuvant chemotherapy is given. ${ }^{26}$ Only women with axillary lymph node-negative, hormone receptor-positive breast cancer, and primary tumors $5 \mathrm{~mm}$ in size or smaller are not recommended to undergo adjuvant hormonal therapy. ${ }^{26}$

For postmenopausal women with endocrineresponsive breast cancer, the $2006 \mathrm{NCCN}$ guidelines recommend 1 of 3 adjuvant endocrine treatment strategies. The options include initial adjuvant therapy for 5 years with either anastrozole or letrozole, switching after 2 to 3 years of tamoxifen to either anastrozole or exemestane to complete 5 years of treatment, or the use of approximately 5 years of tamoxifen followed by 5 years of letrozole therapy. Each of these recommendations is a category 1 recommendation, indicating that they are based on high-level evidence and reflect the uniform consensus of the panel. Based on the current data, the panel is unable to favor one of these treatment options over the other. The use of tamoxifen alone is recommended only in women who decline, have a contraindication to, or who cannot tolerate AIs. Although the guidelines cite the use of specific AIs, the panel recognizes that the thirdgeneration AIs (anastrozole, letrozole, and exemestane) have similar antitumor activity and toxicity profiles, and that any of the 3 may be used in any of the above situations. ${ }^{26}$

\section{ASCO Technology Assessment}

The ASCO Technology Assessment represents a focused evaluation of the use of AIs as adjuvant endocrine therapy in women with hormone receptor-positive breast cancer. The first assessment was issued in 2002, with updates published in 2003 and January 2005..$^{27-29}$ The ASCO technology assessment process incorporates a review of the published literature and materials provided to the committee by the pharmaceutical industry, and then the panel reaches a consensus. The panel is multidisciplinary, including surgeons, medical oncologists, statisticians, and patient advocates. Panel members formally disclose any conflicts of interest.

The initial ASCO Technology Assessment was finalized in May 2002 and stated that the results of the ATAC trial (33 months median follow-up) were insufficient to change standard practice and that 5 years of adjuvant tamoxifen remained the standard endocrine therapy for women with hormone receptor-positive breast cancer. ${ }^{27}$ It suggested that AIs were active and could be used in patients with early-stage breast cancer if, for example, they had a contraindication to tamoxifen. The second ASCO Technology Assessment update included consideration of the 47 months of follow-up data from the ATAC trial and reaffirmed the recommendations from the 2002 technology assessment. ${ }^{28}$ The most recent ASCO Technology Assessment considered the results of the ATAC, ITA, IES, and MA.17 trials, and concluded that optimal adjuvant hormonal therapy for postmenopausal women with hormone receptor-positive breast cancer includes an AI as initial adjuvant therapy or after initial treatment with tamoxifen. ${ }^{29}$ Consistent with the NCCN guidelines, the ASCO Technology Assessment update was not able to identify a single optimal strategy for the adjuvant use of AIs.

\section{St Gallen Consensus}

The St Gallen Consensus represents an international consensus focused on the primary therapy of early breast cancer and is currently updated on a biennial basis. The St Gallen Consensus process includes a series of formal, invited presentations followed by a meeting of a consensus panel that reviews prior $\mathrm{St}$ Gallen recommendations and develops new consensus recommendations. The panel is an invited multidisciplinary group, the most recent of which represented 15 different countries. Conflicts of interest, if any, are not formally disclosed. 
The first St Gallen consensus conference occurred in March 2003 after the release of the ATAC trial. ${ }^{30}$ The consensus stated that a 5-year course of tamoxifen remained standard care for women with hormone receptor-positive breast cancer and that the use of an $\mathrm{AI}$ in postmenopausal women should be limited to women who have contraindications to or cannot tolerate tamoxifen. ${ }^{30}$ When the 2005 St Gallen consensus conference occurred, results were available from the ATAC, BIG 1-98, ITA, IES, MA17, and ABSCG 8/ARNO 95 trials. The 2005 St Gallen Consensus recommends either tamoxifen, initial AI, or initial tamoxifen followed sequentially by an $\mathrm{AI}$ as appropriate endocrine therapy options for treating postmenopausal women with endocrine-responsive breast cancer. ${ }^{31}$ Therefore, the 2005 St Gallen Consensus differs from the 2005 and 2006 NCCN guidelines and the 2005 ASCO Technology Assessment in that tamoxifen alone remains an equivalent option to adjuvant endocrine therapy containing an AI.

\section{Comparison of Updated Guidelines}

The NCCN Breast Cancer Treatment Guidelines, ASCO Technology Assessment, and St Gallen Consensus have all undergone substantial evolution since the initial report in 2001 of the use of adjuvant AIs in treating postmenopausal breast cancer (Table 2). The NCCN Breast Cancer Guidelines and the ASCO
Technology Assessment now state that AIs should be incorporated into the adjuvant therapy of postmenopausal women with endocrine-responsive breast cancer (Table 3). The St Gallen Consensus now states that the use of an AI alone or after initial tamoxifen therapy is an appropriate treatment option. The Consensus continues to consider tamoxifen alone an appropriate treatment option. . $^{25,29,31}$

Both the NCCN Breast Cancer Guidelines and St Gallen Consensus make recommendations encouraging the use of adjuvant cytotoxic chemotherapy before adjuvant endocrine therapy in treating intermediateto high-risk postmenopausal women with endocrineresponsive breast cancer. The ASCO Technology Assessment does not address or suggest any recommendations regarding adjuvant cytotoxic chemotherapy in sequence or concurrently with endocrine therapy. Despite the different methodologies used to develop treatment recommendations for endocrine therapy in postmenopausal women, the current recommendations from these 3 guideline groups and processes are remarkably consistent.

\section{Summary}

Endocrine therapy is the most effective systemic adjuvant therapy in the treatment of hormone receptor-positive invasive breast cancer. Multiple recent trials have shown that the incorporation of the

\begin{tabular}{|c|c|c|c|c|}
\hline Year & $\begin{array}{l}\text { NCCN Breast Cancer } \\
\text { Treatment Guidelines }\end{array}$ & $\begin{array}{l}\text { AsCO Technology } \\
\text { Assessments }\end{array}$ & $\begin{array}{l}\text { St Gallen Consensus } \\
\text { Statements }\end{array}$ & $\begin{array}{l}\text { Al Clinical Trial Reports } \\
\text { Available for Consideration }\end{array}$ \\
\hline 2001 & Tamoxifen & $N / A^{b}$ & Tamoxifen & None \\
\hline 2002 & Tamoxifen or Al & Tamoxifen & N/A & ATAC ${ }^{12,14}$ \\
\hline 2003 & Tamoxifen or Al & Tamoxifen & Tamoxifen & MA. $17^{32}$ \\
\hline 2004 & $\begin{array}{l}\text { Tamoxifen or } \mathrm{Al} \text { or } \\
\text { tamoxifen sequentially } \\
\text { with } \mathrm{Al}\end{array}$ & $\begin{array}{l}\text { Al or tamoxifen } \\
\text { sequentially } \\
\text { with } \mathrm{Al}\end{array}$ & N/A & $\begin{array}{l}\text { ITA }^{19} \\
\text { IES }^{18}\end{array}$ \\
\hline 2005 & $\begin{array}{l}\text { Al or tamoxifen } \\
\text { sequentially with } \mathrm{Al}\end{array}$ & N/A & $\begin{array}{l}\text { Tamoxifen or Al or } \\
\text { tamoxifen sequentially } \\
\text { with Al }\end{array}$ & $\begin{array}{l}\text { ATAC }^{15} \\
\text { ITA }^{22} \\
\text { MA. } 17^{21} \\
\text { ABCSG } 8 \text { and } \\
\text { ARNO } 95^{20}\end{array}$ \\
\hline
\end{tabular}

${ }^{a}$ For postmenopausal women with endocrine-responsive breast cancer.

${ }^{\mathrm{b}} \mathrm{N} / \mathrm{A}=$ no update made in the designated year.

Abbreviations: ABCSG 8, Austrial Breast and Colorectal Cancer Study Group Trial 8; Al, aromatase inhibitor; ARNO 95, Arimidex-Novaldex 95 Trial; ASCO, American Society of Clinical Oncology; ATAC, Arimidex, Tamoxifen, Alone or in Combination; IES, Intergroup Exemestane Study; ITA, Italian Tamoxifen Anastrozole; NCCN, National Comprehensive Cancer Network. 
Carlson et al.

\begin{tabular}{|c|c|c|c|}
\hline & NCCN Treatment Guidelines & ASCO Technology Assessment & St Gallen Consensus \\
\hline Panel members & Experts from member institutions & $\begin{array}{l}\text { Experts chosen for Technology } \\
\text { Assessment Panel }\end{array}$ & International panel of experts \\
\hline Process & $\begin{array}{l}\text { Scheduled annual review and } \\
\text { update of practice guidelines; } \\
\text { feedback from another group } \\
\text { of experts considered; } \\
\text { recommendations incorporated } \\
\text { into treatment algorithm }\end{array}$ & $\begin{array}{l}\text { Annual review with update when } \\
\text { sufficient new evidence is available; } \\
\text { recommendations based on } \\
\text { answering questions }\end{array}$ & $\begin{array}{l}\text { Conference held every } 2-3 \text { y } \\
\text { attracting }>4000 \text { breast cancer } \\
\text { specialists; recommendations } \\
\text { formulated by panel based on } \\
\text { presentations and discussions } \\
\text { at conference }\end{array}$ \\
\hline Tamoxifen use & $\begin{array}{l}\text { Initial adjuvant therapy or alone } \\
\text { for women with contraindications } \\
\text { to aromatase inhibitors (Als) or } \\
\text { who decline using them }\end{array}$ & Option for initial adjuvant therapy & Option for adjuvant therapy \\
\hline Al use & $\begin{array}{l}\text { Preferred option for adjuvant } \\
\text { therapy, either as initial therapy, } \\
\text { switch therapy after } 2-3 \text { y of } \\
\text { tamoxifen, or extended therapy } \\
\text { after } 5 \text { y of tamoxifen }\end{array}$ & $\begin{array}{l}\text { Reasonable alternative to } \\
\text { tamoxifen as initial adjuvant } \\
\text { therapy; treatment of choice for } \\
\text { women with contraindication } \\
\text { to tamoxifen; switch therapy } \\
\text { may be considered after } 2-3 \text { y of } \\
\text { tamoxifen; extended therapy } \\
\text { should be considered based on } \\
\text { residual risk and patient } \\
\text { preference after completing } \\
\text { tamoxifen therapy }\end{array}$ & $\begin{array}{l}\text { Introduced Als in the } \\
\text { treatment of postmenopausal } \\
\text { women with endocrine- } \\
\text { responsive or doubtful } \\
\text { endocrine-responsive disease }\end{array}$ \\
\hline $\begin{array}{l}\text { Updated options } \\
\text { for initial endocrine } \\
\text { therapy }\end{array}$ & $\begin{array}{l}\text { Anastrozole or letrozole } \times 5 \mathrm{y} \text {; } \\
\text { Tamoxifen } \times 2-3 \mathrm{y} \rightarrow \\
\text { exemestane or anastrozole } \\
\times 2-3 \mathrm{y} \text {; Tamoxifen } \times 4.5-6 \mathrm{y} \rightarrow \\
\text { letrozole } \times 5 \mathrm{y} \text {; Tamoxifen } \mathrm{x} 5 \mathrm{y} \\
\text { (for those with } \\
\text { Al contraindication) }\end{array}$ & $\begin{array}{l}\text { Al } \\
\text { Tamoxifen } \rightarrow \text { Al }\end{array}$ & $\begin{array}{l}\text { Low risk: tamoxifen or } \\
\mathrm{Al} \text { or nil } \\
\text { Intermediate risk: } \\
\text { Tamoxifen or } \mathrm{Al} \text {; } \\
\mathrm{CT} \rightarrow \text { tamoxifen or } \mathrm{Al} \text {; } \\
\text { Tamoxifen } \times 2-3 \mathrm{y} \rightarrow \\
\text { exemestane or anastrozole } \\
\text { Tamoxifen } \times 5 \mathrm{y} \rightarrow \text { letrozole } \\
\text { High risk: } \mathrm{CT} \rightarrow \text { tamoxifen or } \\
\mathrm{Al} \text {; } \mathrm{CT} \rightarrow \text { Tamoxifen } \times 2-3 \mathrm{y} \rightarrow \\
\text { exemestane or anastrozole; } \\
\mathrm{CT} \rightarrow \text { Tamoxifen } \times 5 \mathrm{y} \rightarrow \\
\text { letrozole }\end{array}$ \\
\hline
\end{tabular}

selective AIs anastrozole, letrozole, or exemestane, either alone or sequentially with tamoxifen, is associated with superior DFS in postmenopausal women with hormone receptor-positive breast cancer. These trials have provided the impetus for evolution of the prominence and role of selective AIs in evidence-based breast cancer treatment guidelines and technology assessments. Although the development processes differ among the NCCN Breast Cancer Clinical Practice Guidelines in Oncology, the ASCO Technology Assessment on the Use of Aromatase Inhibitors in the Adjuvant Setting, and the St Gallen International Expert Consensus on the Primary Therapy of Early Breast Cancer, all 3 now include AIs as an important component of the treatment of postmenopausal women with receptor-positive breast cancer.

\section{References}

1. Kumar S, Leonard RC. Adjuvant hormonal therapy in early breast cancer. Oncology (Williston Park) 2005;19:1425-1428, 1433.

2. Osborne CK. Tamoxifen in the treatment of breast cancer. N Engl J Med 1998;339:1609-1618.

3. Field MJ, Lohr KN, eds. Clinical Practice Guidelines: Directions for a New Program. Washington DC: National Academy Press, 1990.

4. Browman GP, Levine MN, Mohide EA, et al. The practice guidelines development cycle: a conceptual tool for practice guidelines development and implementation. J Clin Oncol 1995;13: 502-512.

5. Winn RJ, McClure JS. The NCCN clinical practice guidelines in oncology: a primer for users. J Natl Compr Canc Netw 2003; 1:5-13. 
Adjuvant Endocrine Therapy Practice Guidelines

6. Early Breast Cancer Trialists' Collaborative Group. Effects of chemotherapy and hormonal therapy for early breast cancer on recurrence and 15-year survival: an overview of the randomised trials. Lancet 2005;365:1687-1717.

7. Fisher B, Dignam J, Bryant J, Wolmark N. Five versus more than five years of tamoxifen for lymph node-negative breast cancer: updated findings from the National Surgical Adjuvant Breast and Bowel Project B-14 randomized trial. J Natl Cancer Inst 2001;93: 684-690.

8. Fisher B, Dignam J, Bryant J, et al. Five versus more than five years of tamoxifen therapy for breast cancer patients with negative lymph nodes and estrogen receptor-positive tumors. J Natl Cancer Inst 1996;88:1529-1542.

9. Stewart HJ, Prescott RJ, Forrest AP. Scottish adjuvant tamoxifen trial: a randomized study updated to 15 years. J Natl Cancer Inst 2001;93:456-462.

10. Tormey DC, Gray R, Falkson HC. Postchemotherapy adjuvant tamoxifen therapy beyond five years in patients with lymph nodepositive breast cancer. Eastern Cooperative Oncology Group. J Natl Cancer Inst 1996;88:1828-1833.

11. Abrams JS. Tamoxifen: five versus ten years-is the end in sight? J Natl Cancer Inst 2001;93:662-664.

12. Baum M. The ATAC (Arimidex, Tamoxifen, Alone or in Combination) adjuvant breast cancer trial in postmenopausal (PM) women [abstract]. Breast Cancer Res Treat 2001;69:8. Abstract.

13. Baum M, Budzar AU, Cuzick J, et al. Anastrozole alone or in combination with tamoxifen versus tamoxifen alone for adjuvant treatment of postmenopausal women with early breast cancer: first results of the ATAC randomised trial. Lancet 2002;359:2131-2139.

14. Baum M, Buzdar A, Cuzick J, et al. Anastrozole alone or in combination with tamoxifen versus tamoxifen alone for adjuvant treatment of postmenopausal women with early-stage breast cancer: results of the ATAC (Arimidex, Tamoxifen Alone or in Combination) trial efficacy and safety update analyses. Cancer 2003;98:1802-1810.

15. Howell A, Cuzick J, Baum M, et al. Results of the ATAC (Arimidex, Tamoxifen Alone or in Combination) trial after completion of 5 years' adjuvant treatment for breast cancer. Lancet 2005; 365:60-62.

16. Thürlimann BJ, Keshaviah A, Mouridsen H, et al. BIG 1-98: randomized double-blind phase III study to evaluate letrozole (L) vs. tamoxifen $(T)$ as adjuvant endocrine therapy for postmenopausal women with receptor-positive breast cancer [abstract]. J Clin Oncol 2005;23(suppl):6S. Abstract 511

17. Thurlimann BJ. BIG 1-98: randomized double-blind phase III study to evaluate letrozole (L) vs. tamoxifen $(\mathrm{T})$ as adjuvant endocrine therapy for postmenopausal women with receptor-positive breast cancer. Oral presentation presented at the American Society of Clinical Oncology's 41st Annual Meeting. Orlando, Florida, May 13-17, 2005.

18. Coombes RC, Hall E, Gibson LJ, et al. A randomized trial of exemestane after two to three years of tamoxifen therapy in postmenopausal women with primary breast cancer. N Engl J Med 2004;350:1081-1092.

19. Boccardo F, Rubagotti A, Amoroso D, et al. Anastrozole appears to be superior to tamoxifen in women already receiving adjuvant tamoxifen treatment. Abstract presented at the 26th Annual San Antonio Breast Cancer Symposium. San Antonio, Texas, December 3-6, 2005.

20. Jakesz R, Jonat W, Gnant M, et al. Switching of postmenopausal women with endocrine-responsive early breast cancer to anastrozole after 2 years' adjuvant tamoxifen: combined results of ABCSG trial 8 and ARNO 95 trial. Lancet 2005;366:455-462.

21. Goss PE, Ingle JN, Martino S, et al. Randomized trial of letrozole following tamoxifen as extended adjuvant therapy in receptor-positive breast cancer: updated findings from NCIC CTG MA.17. J Natl Cancer Inst 2005;97:1262-1271.

22. Boccardo F, Rubagotti A, Puntoni M, et al. Switching to anastrozole versus continued tamoxifen treatment of early breast cancer: preliminary results of the Italian Tamoxifen Anastrozole Trial. J Clin Oncol 2005;23:5138-5147.

23. Femara [package insert]. East Hanover, NJ: Novartis Pharmaceuticals Corporation, 2004.

24. Carlson RW, Anderson BO, Bensinger W. Breast cancer clinical practice guidelines in oncology. J Natl Compr Canc Netw 2003;1:148-188.

25. Carlson RW, Anderson BO, Burstein HJ, et al. Breast cancer. J Natl Compr Canc Netw 2005;3:238-289.

26. NCCN Breast Cancer Clinical Practice Guidelines in Oncology, version 2, 2006. Available at: http://www.nccn.org/professionals/ physician_gls/PDF/breast.pdf. Accessed October 5, 2006.

27. Winer EP, Hudis C, Burstein HJ, et al. American Society of Clinical Oncology technology assessment on the use of aromatase inhibitors as adjuvant therapy for women with hormone receptor-positive breast cancer: status report 2002. J Clin Oncol 2002;20:3317-3327.

28. Winer EP, Hudis C, Burstein HJ, et al. American Society of Clinical Oncology technology assessment working group update: use of aromatase inhibitors in the adjuvant setting. J Clin Oncol 2003;21: 2597-2599.

29. Winer EP, Hudis C, Burstein HJ, et al. American Society of Clinical Oncology technology assessment on the use of aromatase inhibitors as adjuvant therapy for postmenopausal women with hormone receptor-positive breast cancer: status report 2004. J Clin Oncol 2005;23:619-629.

30. Goldhirsch A, Wood WC, Gelber RD, et al. Meeting highlights: updated international expert consensus on the primary therapy of early breast cancer. J Clin Oncol 2003;21:3357-3365.

31. Goldhirsch A, Glick JH, Gelber RD, et al. Meeting highlights: international expert consensus on the primary therapy of early breast cancer 2005. Ann Oncol 2005;16:1569-1583.

32. Goss PE, Ingle JN, Martino S, et al. A randomized trial of letrozole in postmenopausal women after five years of tamoxifen therapy for early-stage breast cancer. N Engl J Med 2003;349:1793-1802. 